\title{
ON THE OPTIMALITY OF THE STOCK MARKET ALLOCATION OF INVESTMENT *
}

\author{
J. E. Stiglitz
}

I. Introduction, 25. - II. The basic model, 27. - III. Determination of the level of investment in a mean variance model, 32. - IV. Choice of technique, 47. - V. Remarks on alternative models of market equilibrium, 52.VI. Concluding remarks, 55. - Appendix, 57.

\section{INTRODUCTION}

Much of the early literature on market allocations between safe and risky investments suggested that the market would systematically allocate too few resources to risky investments, particularly because many private risks are not social risks. More recently, however, it has been argued that the stock market provides essentially all the risk-pooling possibilities that could be provided, "that the stock market constitutes an allocative mechanism of remarkable efficiency." 1 This has been established more precisely by Arrow and Debreu, ${ }^{2}$ provided that one assumes that there is a complete set of contingent commodities (i.e., in the stock market, at least as many securities as states of nature). There are, however, strong theoretical and empirical grounds on which to object to that assumption. ${ }^{3}$

*An earlier version of this paper was presented at the Far Eastern Meetings of the Econometric Society, Tokyo, 1970. Research support was provided by the Guggenheim, Ford, and National Science foundations. The author is indebted to A. Klevorick, S. Koizumi, P. Kamiya, and M. Jensen for their comments on an earlier draft. M. Jensen and J. Long have reported results similar to those presented here in "On the Inconsistency between 'Optimal' Corporate Investment and Pareto Optimality," mimeo, University of Rochester, 1969.

1. W. J. Baumol, The Stock Market and Economic Efficiency (New York: Fordham University Press, 1965).

2. K. J. Arrow, "The Role of Securities in the Optimal Allocation of Risk Bearing," Review of Economic Studies, vol. 31 (April 1964), pp. 91-96, and G. Debreu, The Theory of Value (New York: John Wiley \& Sons, 1959).

3. For a fuller discussion of them, the reader is referred to J. E. Stiglitz, "Some Aspects of the Pure Theory of Corporate Finance, Bankruptcy, and Take-Overs," paper presented at Hakone (Japan), June 1970; J. E. Meade, The Theory of Indicative Planning (Manchester University Press, 1970); R. Radner, "Competitive Equilibrium under Uncertainty," Econometrica, vol. 36 (Jan. 1968), pp. 31-58; K. J. Arrow, Lecture 3, Some Aspects of the Theory of Risk-Bearing (Helsinki: Yrjö Johnssonin Säätiö, 1965) ; F. H. Hahn, "Equilibrium with Transactions Costs," Econometrica, vol. 39 (May 1971), pp. 417440 . 
When there are fewer securities than states of nature, ${ }^{4}$ three problems immediately arise:

1. How are we to evaluate alternative allocations? In the absence of a full set of Arrow-Debreu securities, the marginal rate of substitution between consumption in different states by different individuals will not in general be equal. Thus, it is not particularly meaningful to compare economies with a full set of Arrow-Debreu markets (which will be Pareto optimal in the conventional sense) with economies lacking such markets. ${ }^{5}$ We propose the following criterion: An allocation will be said to be a (constrained) Paretooptimal allocation if a centralized planner, who was constrained to purchase factors and sell commodities through the given market structures, could not make anyone better off without making someone worse off. ${ }^{6}$

2. What is the objective of each firm? Conventional theory has the firm maximizing its stock market value; prices of the commodities that an individual buys are unaffected by the action of the firm, so by increasing the wealth of the stockholder, the welfare of each stockholder is maximized. This is true whether the individual is a small or a large shareholder in the company. In the absence of a full set of Arrow-Debreu securities, there is no such presumption for value maximization.

3. In order for the individual to evaluate alternative production plans, he must be able to ascertain their effect on the price of a share (on the value of the firm). In the Arrow-Debreu model, there are prices for outputs (inputs) in each state of nature, and the net value of the firm is simply the difference between the value of outputs and inputs using these prices. ${ }^{7}$ But how is the firm to evaluate alterna-

4. The problems discussed here may arise even when there is no uncertainty, e.g., when only a few of the continuum of "qualities" of various commodities that might be produced actually are produced. The analysis of markets for risky assets provides a context in which these questions may be analyzed with somewhat greater clarity and precision than in the more general case. Moreover, it will be clear from the discussion below that the existence of fewer securities than states of nature is neither necessary nor sufficient for all the difficulties that are about to be discussed to occur.

5. As Borch has done; see, e.g., his "The Economics of Uncertainty" in M. Shubik, ed., Essays in Mathematical Economics, In Honor of Oskar Morgenstern (Princeton University Press, 1967), pp. 197-210.

6. This is equivalent to P. Diamond's concept of a "Constrained Pareto Optimal"; i.e., the income delivered to any individual is constrained to be a linear function of the outputs of the different firms in the economy. See P. Diamond, "The Role of a Stock Market in a General Equilibrium Model with Technological Uncertainty," American Economic Review, vol. 57 (Sept. 1967), pp. 759-76.

7. It should be clear that if there are as many independent securities as states of nature, it is equivalent to having a complete set of Arrow-Debreu markets. See D. Cass and J. E. Stiglitz, "The Structure of Preferences and 
tive production plans if there is not a complete set of Arrow-Debreu markets?

This paper is primarily concerned with the third problem. ${ }^{8}$ We shall present a specific example in which there is available a simple and plausible method of evaluation of alternative production plans, in which firms act like competitive price takers, but which, when firms maximize their stock market value, does not lead to an optimal allocation (in the sense defined above). More generally, we shall use our example to give us some insights into why the market allocation resulting from value-maximizing firms is not likely to be optimal.

\section{The Basic Moder}

Before investigating in detail our specific example, we shall outline the basic structure of our economy. Our economy consists of $n+1$ firms (industries) ${ }^{9}$ and $m$ individuals. We shall consider a simple two-period model, in which a single factor input, denoted by $I$ (for investment), is taken in the first period and transformed into a single commodity output the second. ${ }^{1}$ Firms (industries) will differ from one another in the pattern of returns across the states of nature, not in the commodities that they produce. ${ }^{2}$

\section{A. Individual Behavior}

Each individual begins "life" with a given endowment of the factor, $I^{j}$, and a given set of ownership claims on the various firms.

Returns and Separability in Portfolio Allocation: A Contribution to the Pure Theory of Mutual Funds," Journal of Economic Theory, vol. 2 (June 1970), Appendix A, pp. 122-60.

8. The second problem, that of the objective function of the firm, is discussed in J. E. Stiglitz, "Value Maximization and Alternative Objectives of the Firm," mimeo, Cowles Foundation, 1972, and J. E. Stiglitz, "Some Aspects of the Pure Theory of Corporate Finance," op. cit.

9. For most of the analysis, we shall assume that $n$ is fixed. In Section V, we shall consider briefly what happens when $n$ is also determined endogenously. This is discussed at greater length in J. E. Stiglitz, "The Degree of Product Differentiation in Monopolistic Competition: An Example" (forthcoming).

1. At the cost of a slight increase in notational complexity, the model may be easily extended to the case where there is a vector of inputs. The case where there are several outputs introduces an element of price uncertainty. The uncertainty associated with relative prices, though undoubtedly of great importance, introduces additional problems to be discussed elsewhere. See J. E. Stiglitz, "Behavior Towards Risk with Many Commodities," Econometrica, vol. 37 (Oct. 1969), pp. 660-66; J. E. Stiglitz, "A Consumption Oriented Theory of the Demand for Financial Assets and the Term Structure of Interest Rates," Review of Economic Studies, vol. 37 (July 1970), pp. 321-51; and the introductory remarks in P. Diamond, op. cit.

2 . Because of the one-commodity assumption, the only source of uncertainty is technological. See note 1 preceding. 
$\beta_{i}{ }^{j}$ is the proportion of the shares of the $i^{\text {th }}$ firm owned by the $j^{\text {th }}$ individual ${ }^{3}$ at the beginning of the first period $\left(\sum_{j} \beta_{i}{ }^{j}=1\right)$. If the firm were to do no investment in the first period, the individual would receive $\beta_{i}{ }^{j}$ of the output of the firm in the second period. The individual can, of course, sell his ownership claims in the $i^{\text {th }}$ firm to purchase shares in some other firm, and in general we would expect that he will rearrange his "portfolio." Moreover, the value of the individual's initial ownership claims in the $i^{\text {th }}$ firm will depend on the level of investment it undertakes. If the $i^{\text {th }}$ firm invests $I_{i}$, and the total market value of the firm is $V_{i},{ }^{4}$ then the value of the equity of the initial shareholders is $V_{i}-I_{i}$, the total value of the firm less the capital raised to finance the new investment. ${ }^{5}$ The ModiglianiMiller theorem assures that the value of the firm is independent of how it finances its new investment; i.e., it does not depend on the debt-equity ratio of the firm. ${ }^{6}$ Hence the total initial wealth of the $j^{\text {th }}$ individual $W_{0}^{j}$ is just

$$
W_{0}{ }^{j}=I^{j}+\sum_{i} \beta_{i}{ }^{j}\left(V_{i}-I_{i}\right) \text {. }
$$

The individual looks at the various securities that are available ${ }^{7}$

3. Here and elsewhere, we use superscripts $j$ to denote individuals and subscripts $i$ to denote firms. (Later, when there is no ambiguity, we shall drop the superscripts and subscripts.)

4. Our "numeraire" is I. All economic activity (trading and investment decisions) in this model occurs in the first period; hence, we are only concerned with the determination of the value of the firms at that time. Extending the analysis to a multiperiod (in particular, to an infinite time) horizon involves several essential difficulties, including the fact that the value of the firm today depends on its expected value tomorrow, which depends, in turn, on its expected value the day after, and so on; in a deterministic context, these problems have been discussed in K. Shell and J. E. Stiglitz, "The Allocation of Investment in Dynamic Economy," this Journal, vol. 81 (Nov. 1967), pp. 592-609.

5. It may be useful to think of the different firms as different farms operating on indivisible pieces of land. Then ownership claims are on particular pieces of land. The total value of the farm, $V_{i}$, is equal to the value of the land plus the value of the investment on the farm, $I_{i}$.

6. F. Modigliani and M. H. Miller, "The Cost of Capital, Corporation Finance, and the Theory of Investment," American Economic Review, vol. 48 (June 1958), pp. 261-97, and J. E. Stiglitz, "A Re-Examination of the Modigliani-Miller Theorem," American Economic Review, vol. 59 (Dec. 1969), pp. 784-93. Throughout, we make the assumption of no transactions costs and no differential tax treatment of different financial instruments. These are, of course, crucial assumptions. See, e.g., J. E. Stiglitz, "Taxation, Risk-Taking, and the Allocation of Investment in a Competitive Economy," in M. Jensen, ed., Studies in the Theory of Capital Markets (forthcoming).

7. We are explicitly assuming that there are no other assets (and no other sources of income) besides those provided by our $n+1$ firms. The analysis may be extended to these cases, provided, of course, that it still remains true as seems to be the case - that there are fewer securities than states of nature. (As long as marginal rates of substitution of income in one state of nature for that in another remain different for different individuals, there is an incentive to create additional assets. But there are numerous reasons why this does not occur. See note 3 , page 25 above.) 
and allocates his wealth among them so as to maximize his expected utility next period; that is, if $e_{i}(\theta)$ is the return per dollar invested in the $i^{\text {th }}$ risky firm's stock, and $r$ is the return on a safe security (bond), i.e., a security that pays the same amount in every state of nature, and if the individual purchases $V_{i}^{j}$ dollars of the $i^{\text {th }}$ firm's shares, ${ }^{8}$ his income in state $\theta, Y^{j}(\theta)$ is

He chooses $V_{i}^{j}$ to

$$
Y^{j}(\theta) \equiv \sum_{i=1}^{n} V_{i}{ }^{j} e_{i}(\theta)+r\left(W_{0}^{j}-\sum_{i=1}^{n} V_{i}{ }^{j}\right)
$$

$$
\text { maximize } E u\left(Y^{j}(\theta)\right)
$$

where, as usual, we assume the individual is risk averse $\left(u^{\prime}>0\right.$, $\left.u^{\prime \prime}<0\right)$. Thus, the individual's demand for the $i^{\text {th }}$ security will be a function of $e_{1}, \ldots, e_{n}, r$, and $W_{0}{ }^{j}$ :

$$
V_{i}^{j}=D_{i}^{j}\left(e_{1}, \ldots, e_{n}, r, W_{0}^{j}\right) .
$$

(4) differs from the conventional demand functions in that, instead of writing demand as a function of the price of the $i^{\text {th }}$ firm's securities, it is written as a function of the returns per dollar in the $i^{\text {th }}$ security. We can, however, rewrite (4) into a slightly more "conventional" form. Because of the Modigliani-Miller theorem, we can, without loss of generality, assume that the firm issues only shares, so that the total value of equities is equal to the total value of the firm. Thus, the return per dollar invested in the $i^{\text {th }}$ firm is just equal to the total returns to the $i^{\text {th }}$ firm divided by the total value of its equities.

$$
e_{i}(\theta)=X_{i}(\theta) / V_{i}, \quad r=X_{s} / V_{s}
$$

where $X_{i}(\theta)$ is the total return to the $i^{\text {th }}$ firm in state $\theta$. The subscript $s$ denotes the riskless industry. ${ }^{9}$ Substituting (5) into (4), we obtain

$$
V_{i}^{j}=D_{i}{ }^{j *}\left(V_{1}, \ldots, V_{n}, V_{s} ; X_{1}, \ldots, X_{n}, X_{s}, W_{0}{ }^{j}\right) .
$$

Finally, summing over all individuals, we obtain the market "demand" functions

$$
\begin{aligned}
& V_{i}{ }^{d} \equiv \Sigma V_{i}{ }^{j}=\Sigma D_{i}{ }^{j *}= \\
& D^{*}{ }_{i}\left(V_{1}, \ldots, V_{n}, V_{s} ; X_{1}, \ldots, X_{n}, X_{s} ; W_{0}{ }^{1}, \ldots, W_{0}{ }^{m}\right) .
\end{aligned}
$$

8. We allow short sales and borrowing, i.e.,

$$
V_{i}^{j} \lessgtr 0, W_{0}^{j}-\sum_{i=1}^{n} V_{i}^{i} \gtrless 0 \text {. }
$$

9. Throughout this paper we assume the existence of a perfectly safe firm. The analysis may easily be modified if there is no such firm, provided that there exists a safe security (bonds with no default risk); the market allocation will still be nonoptimal. We make the assumption of the existence of a safe industry because one of the questions on which we wish to focus is whether there is a systematic misallocation of resources to the safe industry relative to the risky. 
We have thus characterized the "demand" side of the market. We now turn to a more detailed description of the firms.

\section{B. Firm Behavior}

Each firm is characterized by a production technology, which specifies the output in state $\theta$, if the firm invests $I_{i}$ and chooses production plan $\xi_{i}$ :

$$
X_{i}(\theta)=X_{i}\left(\theta, I_{i}, \xi_{i}\right)
$$

Alternative production plans, for instance, for a farm, might be whether to use a fertilizer, which will increase output (for given level of input) in those states of nature when it rains, but decreases it in a drought.

The firm chooses a level of investment and its production plan in order to maximize the stock market value of its initial shareholders, $V_{i}-I_{i}{ }^{1}$ The difficulty is to determine what will be the effects on the stock market valuation of a risky firm of a change in its investment level or production plan. We shall call the relationship between the market value perceived by the firm and the level of investment and production plan its valuation function. If there were a complete set of Arrow-Debreu prices - so that $q(\theta)$ is the price today of a promise to deliver one dollar next period if state $\theta$ occurs - the calculation of $V_{i}$ would be straightforward:

$$
V_{i}=\Sigma_{\theta} X_{i}(\theta) q(\theta) \text {. }
$$

If there were not a complete set of Arrow-Debreu markets, but there were as many independent firms as states of nature, then the firm could infer the market evaluation of income in each state of nature; that is, if the firm knew the market valuation of $v$ other firms (where $v$ is the number of states of nature) and their outputs in each state of nature, then it could solve for that set of $q(\theta)$ which would make

$$
V_{i}=\sum_{\theta=1}^{v} q(\theta) X_{i}(\theta) \quad i=1, \ldots, v \leqslant n,
$$

i.e., in vector notation ${ }^{2}$

$$
q(\theta)=V \cdot X^{-1} .
$$

1. As we noted in the introduction, it is not obvious that, when there are fewer securities than states of nature, value maximization is in the interests of the shareholders. Our motivation in using that assumption here is to make the results of our model as comparable as possible to those of the conventional Arrow-Debreu model; and because it is a behavioral rule that has often been suggested firms ought to use, we believe it is worthwhile pursuing its implications. See, e.g., I. Fisher, The Theory of Interest (New York: Macmillan Co., 1930); M. Jensen and J. Long, op. cit.; F. Modigliani and M. Miller, op. cit.; and J. E. Stiglitz, "Value Maximization," op. cit.

2. The assumption of "independent firms" assures us that $X^{-1}$ exists. For 
Notice that in this case the firm has to have knowledge about both the outputs of other firms in each state and their market valuations.

But, as we noted in the introduction, not only is there no complete set of Arrow-Debreu securities, there are fewer firms than states of nature.

In the example to be analyzed in detail below, there is, however, another natural valuation function. For the moment, our concern is understanding the basic structure of the model. For this, all we need is to postulate some valuation function of the firm that leads to a determinate level of investment, $I_{i}$, as a function of the outputs and market valuations of the other firms, or some marketdetermined parameters (such as $q(\theta)$ in the Arrow-Debreu model).$^{3}$

\section{Market Equilibrium}

Finally, we come to a statement of the conditions for equilibrium of our economy. An equilibrium is described by a set of firm valuations, $V_{i}$, investment levels, $I_{i}$, and choices of plans, $\xi_{i}$, such that given the levels of investment, firm valuations, and choices of plans of all of the other firms, each firm believes that it is maximizing the stock market value of its initial shareholders; such that

$$
\sum_{i} I_{i}=\sum_{j} I^{j}
$$

the sum of investment demands is equal to the total factor supply; and such that the demands for the different securities (taking the return per dollar of the firm in each state of nature as given) add up to the supply of securities,

$$
V_{i}=V_{i}{ }^{d} \equiv V_{i}{ }^{j}
$$

To recapitulate: we are concerned with the determination of the equilibrium in the $n+2$ markets in the first period - the $n+1$ markets for securities and the market for the factor. In the second period there is no economic activity; individuals simply receive and consume the commodities that they have "contracted" for by their purchases of various securities. At the beginning of the first period, individuals have claims on the various firms and given supplies of the factor. These they trade among themselves. Firms purchase

a more extended discussion of the relation between market securities and Arrow-Debreu securities, see D. Cass and J. E. Stiglitz, "The Structure of Preferences and Returns and Separability in Portfolio Allocation," op. cit., and D. Cass and J. E. Stiglitz, "Risk Aversion and Wealth Effects on Portfolios with Many Assets," Review of Economic Studies (forthcoming).

3 . We need to impose one further condition on the firm evaluation function: in equilibrium, the price that the firm "predicts" for itself at the level of investment and for the production plan it undertakes must be the value actually obtained. 
these factors, in return giving claims on their output next period. The levels of investment and choices of production plans are made to maximize the value of the original shareholders' equity, where the valuation is determined by some (as yet unspecified) valuation function. Equilibrium requires that investment by firms equal the supply of $I$ by individuals (equilibrium in the factor market) and "exchange equilibrium" - at the given market prices of the securities no individual wishes to exchange his ownership claims on one firm for ownership claims on another. The timing and notation is set out in Table I.

What remains to be done is a precise specification of the firm's valuation function. We do this in the context of a specific example that has played a central role in the development of the literature on uncertainty and portfolio analysis: the mean variance model.

\section{Determination of the Level of Investment in a Mean Variance Model}

\section{A. Individual Behavior}

We shall assume that the individual evaluates alternative patterns of income in terms of mean, $E Y$, and variance $\sigma_{Y}{ }^{2}$; if $u(Y)$ is his utility function in terms of income, then

$$
E u(Y)=U\left(E Y, \sigma_{Y}\right)
$$

where

$$
\sigma_{Y}^{2}=E(Y-E Y)^{2}
$$

The justifications and limitations of this assumption have been analyzed in detail elsewhere. ${ }^{4}$ In order to focus on the problem at hand, we shall assume that all individuals have correct (and hence identical) expectations about the output of each firm in each state of nature. Moreover, to facilitate comparisons between the market and optimal allocations, we shall assume that all individuals are identical. ${ }^{5}$

When individuals' expected utility can be written as a function

4. In particular, we require either that individuals have a quadratic utility function or that the joint probability distribution of all returns is a multivariate normal distribution. For a discussion of the sufficiency of these conditions, see J. Tobin, "Liquidity Preference as Behavior Towards Risk," Review of Economic Studies, vol. 25 (Feb. 1958), pp. 65-86, and "The Theory of Portfolio Selection," in Hahn and Brechling, eds., The Theory of Interest Rates (London: Macmillan, 1965) pp. 3-51. For a discussion of the necessity of these conditions, see M. Rothschild and J. E. Stiglitz, "Increasing Risk: A Definition," Journal of Economic Theory, vol. 2 (Sept. 1970), pp. 225-43. cit.

5. This assumption may, however, be easily removed. Cf. P. Diamond, $o p$. 





of the mean and standard deviation of income, it is well known that we can reduce the portfolio allocation problem to two separate problems: (a) finding the proportion of wealth to invest in the safe asset, and (b) finding the proportions in which to invest in the alternative risky assets. ${ }^{6}$ Indeed it can be shown ${ }^{7}$ that all individuals, independent of their utility function, initial endowments, etc., will purchase the risky assets in the same proportion given by

$$
\frac{\lambda_{i}}{\lambda_{j}}=\frac{\sum_{k}\left(\mu_{k}-r\right) \sigma_{k i}^{\prime}}{\sum_{k}\left(\mu_{k}-r\right) \sigma_{k j}^{\prime}}
$$

where $e_{i}(\theta)=$ return per dollar invested in $i^{\text {th }}$ risky asset in state $\theta$, $i=1, \ldots, n$.

$\mu_{i}=E e_{i}=$ average return per dollar invested in $i^{\text {th }}$ risky asset.

$\sigma_{i j}=E\left(e_{i}-\mu_{i}\right)\left(e_{j}-\mu_{j}\right)=$ covariance of returns of $i^{\text {th }}$ and $j^{\text {th }}$ firms (per dollar invested in each).

$\sigma_{i i}=$ variance of $i^{\text {th }}$ security per dollar invested.

$\boldsymbol{\sigma}^{\prime}{ }_{i j}=$ cofactor of $i j^{\text {th }}$ element of the inverse of $\left\{\boldsymbol{\sigma}_{i j}\right\}$.

$\lambda_{i}=$ proportion of total assets invested in $i^{\text {th }}$ risky asset.

$r=$ return per dollar invested in safe bond (riskless firm).

We shall denote by $\sigma_{R}$ and $\mu_{R}$ the standard deviation and mean of the return per dollar invested in the optimal risky portfolio; let $\lambda^{*}{ }_{i}$ equal the optimal proportion of risky assets held in the $i^{\text {th }}$ security. Then

$$
\begin{aligned}
& \mu_{R} \equiv \Sigma \Sigma \lambda^{*}{ }_{i} \mu_{i} ; \\
& \sigma_{R}=\sum_{i} \sum_{j} \lambda^{*}{ }_{i \sigma_{i j}} \lambda^{*}{ }_{j} .
\end{aligned}
$$

The remaining portfolio allocation problem is what percentage, $a$, of one's wealth to allocate to the risky assets. We choose $a$ to maximize

$$
E U\left(W_{0}\left(\alpha \mu_{R}+(1-a) r\right), a \sigma_{R} W_{0}\right) \equiv E U\left(E Y, \sigma_{Y}\right) .
$$

6. This is just the portfolio separation theorem, originally proved by Tobin, op. cit. For a complete discussion and generalization of this theorem, see D. Cass and J. E. Stiglitz, "The Structure of Preferences and Returns and Separability in Portfolio Allocation," op. cit.

7. Let $\lambda=\left(\lambda_{1}, \ldots, \lambda_{n}\right), \mu=\left(\mu_{1}, \ldots, \mu_{n}\right)$. Then $E Y \equiv W_{0}(r+\lambda \cdot(\mu-r))$, and $\sigma_{Y}=\lambda \sigma \lambda^{\prime} W_{0}^{2}$. An efficient portfolio must minimize variance for any given mean; forming the Lagrangian

(13) $L \equiv \lambda \sigma \lambda^{\prime} W_{0}^{2}+q^{\prime}\left(M-(\lambda \cdot(\mu-r)+r) W_{0}\right)$,

we obtain the following necessary conditions:

(14) $\lambda \sigma=q(\mu-r)$

where $q=q^{\prime} / W_{0}$, or

(14') $\quad \lambda=q(\mu-r) \sigma^{-1}$.

Equation (15) follows immediately. 
Hence

$$
-\frac{U_{1}}{U_{2}}=\frac{\sigma_{R}}{\mu_{R}-r}
$$

The marginal rate of substitution between mean and standard deviation must equal the "adjusted" coefficient of variation, taking the safe asset as the origin. The portfolio allocation is described in the familiar mean variance diagram (Figure I), where the shaded area

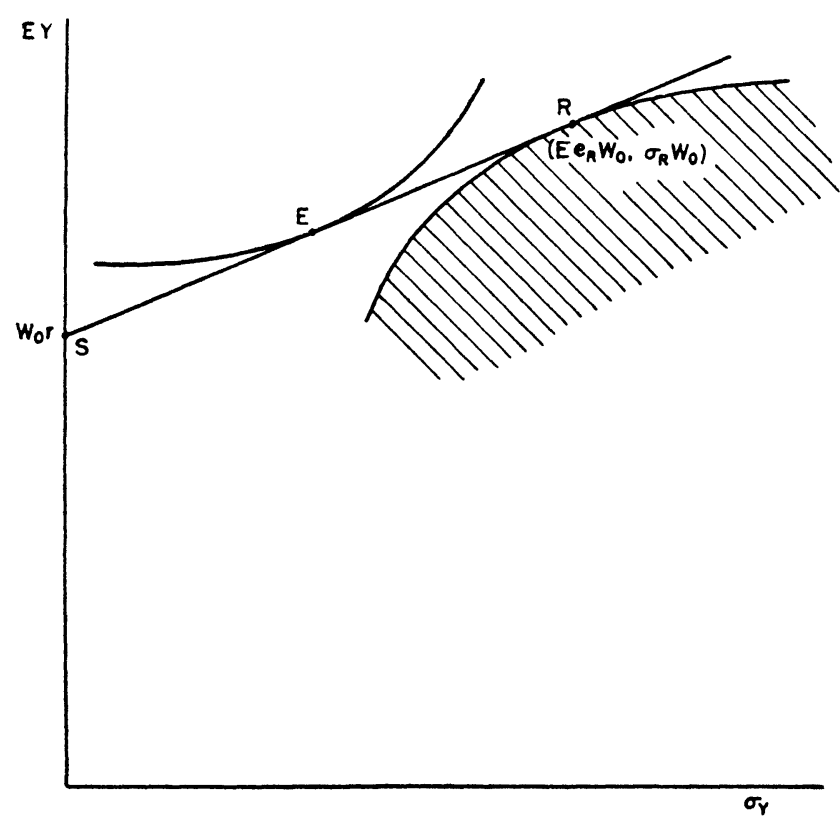

Figure I

Individual's Portfolio Allocation

gives all possible mean standard deviations from investing only in the risky assets in different proportions, $R$ gives the optimal risky portfolio, $S$ denotes terminal wealth if all were invested in the safe asset, and $S R$ gives the opportunity locus. $E$ is the equilibrium.

\section{B. Equilibrium Market Valuations}

The great advantage of using the mean variance model is that, in equilibrium, the values of the different firms will be related to one another in a simple and intuitively plausible way: for each firm, we can calculate the certainty equivalent of its uncertain income; the market valuation is just the certainty equivalent return discounted 
by the safe rate of return, $r$. The certainty equivalent of its income is just its mean return less a risk discount factor times the "riskiness" of the firm's income, where "riskiness" is simply the sum of its own variance plus its covariance with all other firms. Hence ${ }^{8}$

$$
V_{i}=\frac{E X_{i}-k \Sigma E\left(X_{i}-E X_{i}\right)\left(X_{j}-E X_{j}\right)}{r}
$$

where $k$ is the risk discount factor. ${ }^{9}$ It is important to observe that $k$, like any other "price," is the same for all firms.

This valuation formula has one important property to which attention should be drawn: observe that if we have two perfectly correlated firms, so $z X_{i}(\theta)=X_{k}(\theta)$, then $V_{k}(\theta)=z V_{i}(\theta)$, just as we would expect. ${ }^{1}$ On the other hand, if $X_{i}$ is not perfectly correlated with $X_{k}$ and if $X_{k}$ has $z$ times the mean and standard deviation of $X_{i}$, and the two firms are equally correlated with the rest of the market, $V_{k}$ will be less than $z$ times $V_{i}$. This is a natural result from risk aversion and the consequent desire for diversification by individuals. If the two firms were "identically distributed" (but not perfectly correlated) and if the value were proportional to the size (so that mean and standard deviation of the return per dollar were the same), all individuals would want to hold the securities of the two firms in equal amounts; hence, if the demand for securities of

8. This result was originally established by J. Lintner, "The Valuation of Risk Assets and the Selection of Risky Investments in Stock Portfolios and Capital Budgets," Review of Economics and Statistics, vol. 47 (Feb. 1965), pp. 13-37, and W. F. Sharpe, "Capital Asset Prices: A Theory of Market Equilibrium under Conditions of Risk," Journal of Finance, vol. 19 (Sept. 1964), pp. 425-42. See also J. Mossin, "Equilibrium in a Capital Asset Market," Econometrica, vol. 34 (Oct. 1966), pp. 768-83.

This result follows by substituting (5) into (14) to obtain, e.g.,

$$
\sum_{k} E \lambda_{k}{ }^{j}\left(\frac{X_{i}}{V_{i}}-\frac{E X_{i}}{V_{i}}\right)\left(\frac{X_{k}}{V_{k}}-\frac{E X_{k}}{V_{k}}\right)=q^{j}\left(\frac{E X_{i}}{V_{i}}-r\right) \text {. }
$$

Multiplying by $V_{i}$, we obtain

$$
\frac{1}{W_{0}^{j} q^{j}} \Sigma \frac{\lambda_{k}^{j} W_{0}^{j}}{V_{k}}\left(X_{i}-E X_{i}\right)\left(X_{k}-E X_{k}\right)=E X_{\imath}-r V_{\imath} \text {. }
$$

Summing over all $j$, and observing that in equilibrium

we obtain

$$
\sum_{j} \lambda_{k}{ }^{j} W_{0}^{j}=V_{k}
$$

$$
\frac{1}{\Sigma W_{0}^{j} q^{j}} \Sigma\left(X_{i}-E X_{i}\right)\left(X_{k}-E X_{k}\right)=E X_{i}-r V_{i},
$$

from which we can immediately derive (19).

9. By summing (19) over all $i$, we obtain the result that

$$
k=\frac{\Sigma E X_{i}-r \Sigma V_{i}}{\sum_{i} \sum\left(X_{i}-E X_{i}\right)\left(X_{j}-E X_{j}\right)} \text {. }
$$

1. $V_{i}=\left\{E X_{i}-k \underset{j \neq i, k}{\sum} E\left(X_{i}-E X_{i}\right)\left(X_{j}-E X_{j}\right)+E\left(X_{i}-E X_{i}\right)^{2}(1+z)\right\} / r$

$$
V_{k}=\left\{z E X_{i}-k\left(\sum _ { j \neq i , k } z \left(E\left(X_{i}-E X_{i}\right)\left(X_{j}-E X_{j}\right)\right.\right.\right.
$$

$$
\left.+E\left(X_{i}-E X_{i}\right)^{2}\left(z^{2}+z\right)\right\} / r=z V_{i} \text {. }
$$


the smaller firm equaled the supply (i.e., equaled the value of the firm), demand would be less than supply for the larger. Hence, market clearing requires the larger firm to have a value that is less than proportional to its size; the mean and standard deviation of the return per dollar invested must be greater for the larger firm than for the smaller to induce individuals to hold a larger proportion of their portfolio in that firm.

The proportionality factor $k$ will in general depend on the vectors $I^{j}$ and $\beta_{i}{ }^{j}$, the number and preferences of individuals in the economy, and the patterns of outputs of the different firms, $X_{i}(\theta)$. But in two special cases, $k$ takes on a very simple form:

(a) If all individuals have a quadratic utility function, i.e., $w^{j}\left(Y^{j}\right)=-e^{-a j Y j}$

then ${ }^{2}$

$$
k=\frac{1}{\Sigma \frac{1}{c^{j}}-\Sigma E X_{i}} .
$$

(b) If all individuals have constant absolute risk aversion, i.e.,

$$
u^{j}\left(Y^{j}\right)=-e-a^{j} Y^{j}
$$

and if all $x_{i}$ are jointly normally distributed, so that $Y^{j}$ is normally distributed, with mean $E Y$ and variance $\sigma_{Y}{ }^{2}$, then

$$
U^{j}\left(E Y, \sigma_{Y}\right)=E u^{j}=-\exp \left\{-a^{j} E Y^{j}+a^{j 2} \sigma_{Y}^{2} / 2\right\},
$$

from which it follows that ${ }^{3}$

2. This may be proved as follows: we can write

$$
Y^{j}(\theta)=\left(\Sigma \lambda_{i}^{j}\left(e_{i}-r\right)+r\right) W_{0}^{j}=\Sigma \gamma_{i}^{j}\left(X_{i}-r V_{i}\right)+r W_{0}^{j}
$$

where $\gamma_{i}{ }^{j} \equiv \lambda_{i}{ }^{j} W_{0}^{j} / V_{i}=V_{i}^{j} / V_{i}=$ share of $i^{\text {th }}$ firm owned by $j^{\text {th }}$ individual (after allocating his portfolio optimally). Hence, optimal choice of $\lambda_{i}{ }^{j}\left(\gamma_{i}{ }^{j}\right)$ implies $\frac{\partial E U^{j}}{\partial \gamma_{i}^{j}}=E\left\{\left(X_{i}-r V_{i}\right)-c^{j}\left(\Sigma\left(X_{i}-r V_{i}\right)\left(X_{k}-r V_{k}\right) \gamma_{k}^{j}+W_{0}^{j} r\left(X_{i}-r V_{i}\right)\right)\right\}=0$.

Rewriting $X_{j}-r V_{j}=X_{j}-\stackrel{k}{E} X_{j}+E X_{j}-r V_{j}$, and summing over all $j$, we obtain

$$
\begin{aligned}
\left(\Sigma\left(\frac{1}{c^{j}}-r W_{0}^{j}\right)\right)\left(E X_{i}-r V_{i}\right) & =\Sigma_{k} E\left(X_{i}-E X_{i}\right)\left(X_{k}-E X_{k}\right) \\
& +\left(E X i-r V_{i}\right) \sum_{k}\left(E X_{k}-r V_{k}\right) .
\end{aligned}
$$

Upon observing that $\Sigma V_{k}=W_{0}^{j}$ we obtain

$$
\frac{\partial \ln E u^{j}}{\partial \gamma_{i}^{j}}=a^{j}\left(E X_{i}-r V_{i}\right)-a_{k}^{j 2} \Sigma\left(X_{i}-E X_{i}\right)\left(X_{k}-E X_{k}\right) \gamma_{k}^{j}=0 \text {. }
$$

3. This follows by taking

$$
\left(E X_{\imath}-r V_{i}\right)\left(\Sigma \frac{1}{c^{j}}-\Sigma E X_{k}\right)=\Sigma \cdot E\left(X_{i}-E X_{i}\right)\left(X_{k}-E X_{k}\right) \text {. }
$$

Summing over $j$, we obtain

$$
\left(\Sigma \frac{1}{a^{j}}\right)\left(E X_{\imath}-r V_{\imath}\right)=E\left(X_{\imath}-E X_{\imath}\right)\left(X_{k}-E X_{k}\right) \text {. }
$$

The reason that $k$ takes on such a simple form here is that the demand for risky assets does not in this special example depend on the level of wealth. 
$\left(20^{\prime}\right)$

$$
k=1 / \Sigma\left(1 / a^{j}\right)
$$

Notice that in both cases the variance of the available securities does not affect the size of $k$; however, increasing the number of individuals among whom the risks are spread does reduce $k .^{4}$

For later reference, it will be useful to express $k$ in terms of the marginal rate of substitution of individuals between mean and standard deviation. Since all individuals hold the risky assets in the same proportions, we can aggregate all the risky firms together. Let $V_{R}$ be the value of the aggregate risky portfolio,

From (18)

$$
\begin{aligned}
V_{R} & =\sum_{i=1}^{n} V_{i}, X_{R}=\sum_{i} X_{i}, \mu_{R}=E X_{R} / V_{R}, \sigma_{R}^{2} \\
& =E\left(X_{R}-E X_{R}\right)^{2} / V^{2} .
\end{aligned}
$$

$$
\frac{E X_{R} / V_{R}-r}{\sigma_{R}}=-\frac{U_{2}}{U_{1}}
$$

i.e.,

$$
V_{R}=\frac{E X+\left(U_{2} / U_{1}\right)\left(E\left(X_{R}-E X_{R}\right)^{2}\right)^{1 / 2}}{r} .
$$

Comparing (19) and (21), we immediately observe that

$$
k=\frac{-U_{2}}{U_{1}\left(E\left(X_{R}-E X_{R}\right)^{2}\right)^{1 / 2}} .
$$

$k$ equals the marginal rate of substitution of mean for standard deviation divided by the standard deviation of the risky assets; equivalently, it is twice the marginal rate of substitution of mean for variance. $^{5}$

\section{Firm Behavior}

In the previous subsection, we derived the relative valuations of different firms, given $X_{i}(\theta)$ (i.e., given their investment level and choice of production plan). We now turn to the crucial question of the determination of the firm's decisions. We begin our analysis

See Cass-Stiglitz, "The Structure of Preferences and Returns and Separability," op. cit.

4. A similar observation (in a different context) was made by P. A. Samuelson, "Risk and Uncertainty: A Fallacy of Large Numbers," Scientia (April-May 1963), 6th Series, 57th year, pp. 1-6.

5. It should be clear that, although we originally expressed our utility function in terms of mean and standard deviation, it was an arbitrary choice based primarily on considerations of analytical convenience; we could as easily have written

$$
E u=v\left(E Y, \sigma_{Y}^{2}\right)
$$

and conducted our analysis in terms of $v$ rather than $\mu$. 
with the special case where the firm's only decision is $I_{i}$. We shall, moreover, assume that all firms are independent, i.e.,

(23) $\quad E\left(X_{i}-E X_{i}\right)\left(X_{j}-E X_{j}\right)=0, i \neq j$.

Thus if $\sigma_{X_{i}}{ }^{2}=E\left(X_{i}-E X_{i}\right)^{2}$, the value of the firm in equilibrium will depend only on $E X_{i}$ and $\sigma_{X_{i}}$, and the market parameters $r$ and $k$ :

$$
V_{i}=\frac{E X_{i}-k \sigma_{X_{i}}{ }^{2}}{r}
$$

To describe the technology of the $i^{\text {th }}$ firm, we need only to specify how the mean and variance depend on the investment level:

$$
\begin{aligned}
& E X_{i}\left(I_{i}\right)=h_{i}\left(I_{i}\right) \\
& \sigma_{X_{i}}\left(I_{i}\right)=g_{i}\left(I_{i}\right) .
\end{aligned}
$$

Increasing investment leads to increased average returns, but at a declining rate,

(26a) $\quad h_{i}^{\prime}>0, \quad h^{\prime \prime}{ }_{i} \leqslant 0$,

while standard deviation is an increasing convex function of $I_{i}$, (26b) $\quad g^{\prime}{ }_{i}>0, \quad g_{i}^{\prime \prime} \geqslant 0$.

(All that we really require is that $g^{\prime \prime}{ }_{i} g_{i}+g^{\prime}{ }_{i}^{2} \geqslant 0$. For the safe industry, $g_{s} \equiv 0$.)

The firm chooses its investment level to maximize the stock market value of its initial shareholders, i.e., if $V_{i}\left(I_{i}\right)$ is the value of the firm when its investment level is $I_{i}$, then

$$
\frac{d\left(V_{i}-I_{i}\right)}{d I_{i}}=0
$$

or

$$
\frac{d V_{i}}{d I_{i}}=1
$$

For the safe industry, this implies that if it acts competitively and takes the rate of interest as given, so that

then

$$
V_{s}=h_{s}\left(I_{s}\right) / r
$$

(28a) $\quad h^{\prime}\left(I_{s}\right)=r$.

The rate of return on a safe investment is just equal to the marginal productivity of investment in the safe industry. This is as it should be.

For the risky firms, the calculation of the consequences of alternative investment levels is only slightly more complicated. The firm calculates the certainty equivalent of its random output at 
alternative investment levels, $\chi_{i}\left(I_{i}\right)$. Its value is just

$$
V_{i} \equiv \frac{\chi_{i}\left(I_{i}\right)}{r}
$$

so

$$
\chi^{\prime}{ }^{\prime}=r .
$$

The certainty equivalent is just the mean minus a "risk premium," where the "risk premium" is just the variance times a "risk discount factor." In other words, we can think of firms as selling two commodities, mean and variance, which have "prices" $1 / r$ and $-k / r$, respectively (i.e., an increase in the variance reduces the value of the firm). If firms take these prices ( $k$ and $r$ ) as given, maximization of stock market valuations implies (from (24) and (27))

$$
\frac{h_{i}^{\prime}\left(I_{i}\right)-2 k g^{\prime}\left(I_{i}\right) g_{i}}{r}=1 \text {. }
$$

Because of assumptions (26), (28) can be inverted:

$$
I_{i}=I_{i}(k, r)
$$

with

and

$$
\text { (30b) } \quad \frac{\partial I_{i}}{\partial r}=\frac{1}{h^{\prime \prime}{ }_{i}-k\left(g^{\prime \prime}{ }_{i} g_{i}+g^{\prime}{ }^{2}\right)}<0 \text {. }
$$

\section{Market Equilibrium}

The total competitive market equilibrium for the mean variance model may now be easily described. (28) defines the level of investment for each value of $r$ and $k$. For each value of $r$ and $k$ that clears the investment market, i.e.,

$$
I_{d}(r, k) \equiv \Sigma_{i} I_{i}(r, k)=\Sigma I_{j} \equiv I,
$$

(19) defines a value of $r$ and $k$ that will clear the securities market. A value of $r$ and $k$ and the associated values of $I_{i}$ and $V_{i}$ simultaneously satisfying $\left(10^{\prime}\right)$ and (19) is a competitive equilibrium.

The market equilibrium may be depicted graphically for the case where all $m$ consumers are identical and all the firms in the risky industry are identical (but independently distributed). Clearly, the level of investment in each of the risky firms will be identical.

First, we describe the mean variance opportunity locus. If $I_{R}$ is the total amount invested in the risky industries, the mean and variance of output second period per capita are given by 
(31a) $E Y=\left\{h_{s}\left(I-I_{R}\right)+h_{R}\left(I_{R}\right)\right\} / m$

(31b) $\quad \sigma_{Y}^{2} \equiv \frac{g_{R}{ }^{2}\left(I_{R}\right)}{m^{2}} \equiv \frac{n}{m^{2}} g_{i}^{2}\left(I_{R} / n\right)$

where

$$
h_{R}\left(I_{R}\right) \equiv n h_{i}\left(I_{R} / n\right) .
$$

Under the assumptions about our technology given in (26), in the relevant region, where increasing the allocation to the risky industries increases mean as well as variance, i.e.,

$$
\frac{d E Y}{d \sigma_{Y}}=\frac{h_{R}^{\prime}-h_{s}^{\prime}}{g^{\prime}{ }_{R}}>0
$$

the opportunity locus is concave ${ }^{6}$ as depicted in Figure II.

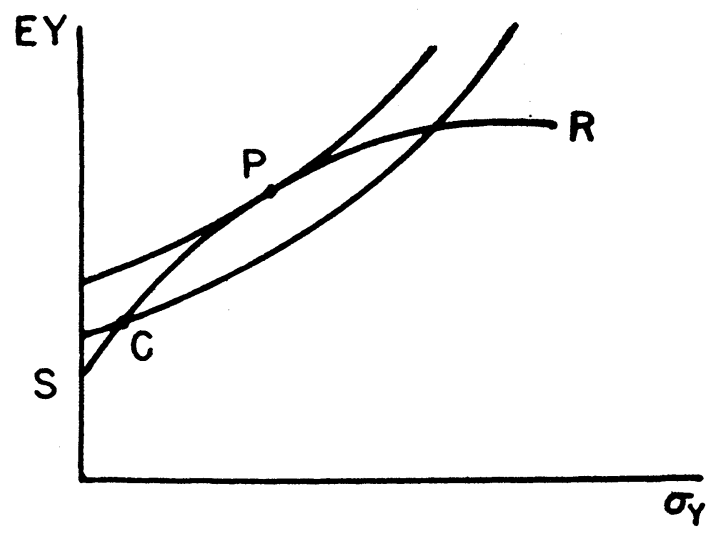

Figure II

Market and Optimal Allocation of Investment

By increasing $r$ and decreasing $k$, we can generate all points on the opportunity locus (using $\left(10^{\prime}\right)$ and $(30)$ ). We can then calculate what the slope of the indifference curve through the given point would have to be to induce individuals to hold the given securities in the amount supplied. Using (22), we have

$$
-\frac{U_{2}}{U_{1}}=k g_{R}\left(I_{R}\right) \text {. }
$$

(33) should be compared with (32). Substituting (28) into (32) we obtain

$$
\frac{d E Y}{d \sigma_{Y}}=2 k g_{R}\left(I_{R}\right)
$$

so the slope of the opportunity locus is always twice as great as the

$$
\text { 6. } \frac{d^{2} E Y}{d \sigma_{Y}{ }^{2}}=\left(\frac{h^{\prime \prime}{ }_{R}+h^{\prime \prime} s_{s}}{g^{\prime}{ }_{R}}-\frac{d E Y}{d \sigma_{Y}} \frac{g^{\prime \prime}{ }_{R}}{g_{R}^{\prime}}\right) \frac{m}{g_{R}^{\prime}}<0 \text {. }
$$


slope of the indifference curve that would sustain the given point on the opportunity locus. Point $C$ denotes a competitive equilibrium for our example.

There is nothing that we have said so far that ensures an interior equilibrium; i.e., it is possible to have a market equilibrium with only safe or risky industries, as depicted in Figures IIIa and $b$. From now on, however, we shall focus on interior equilibria.

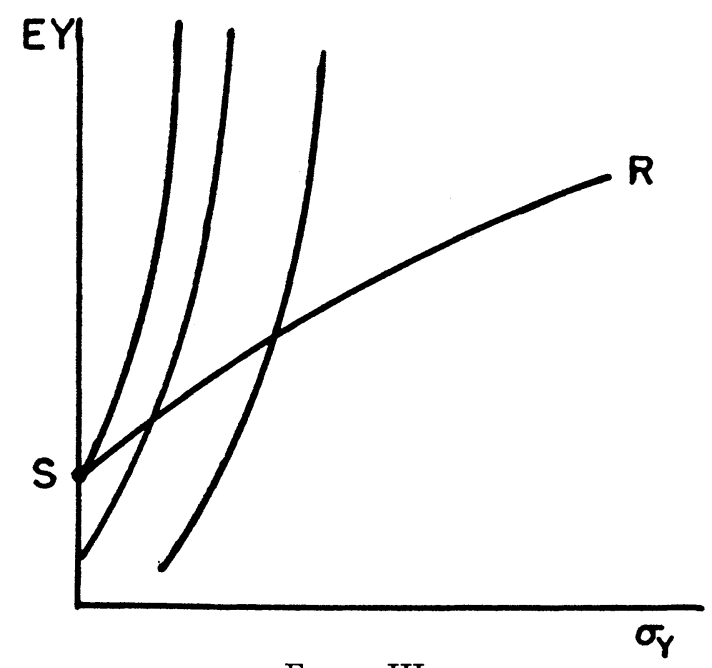

Figure IIIa

Specialization in Risky Industries



Figure IIIb

Specialization in Safe Industry 
It is easy to calculate the solution explicitly for the two cases of quadratic and constant absolute risk aversion presented above. In the latter case, $\left(20^{\prime}\right)$ states that market equilibrium requires $k=$ $1 / \Sigma\left(1 / a^{j}\right) \equiv k^{*}$. Thus, we simply find that value of $r$ for which

$$
I_{d}\left(r, k^{*}\right)=I \text {. }
$$

If

(36a) $I(0, k)=\infty$,

(36b) $\quad I(\infty, k)=0$

we can always find a unique value of $0<r<\infty$ satisfying $(35) .^{7}$ If $h^{\prime}{ }_{s}(0)>r^{*}>h^{\prime}{ }_{s}(I)$, then the equilibrium is interior.

Similarly, for the quadratic utility function, $k$ must satisfy (20). To "solve" diagrammatically for the equilibrium values of $r$ and $k$, observe that the investment market-clearing equation defines a negatively sloped curve between $r$ and $k$, which (under assumption (36b)) hits the horizontal axis at a finite value of $r \equiv r_{\max }$, beyond which, even at a zero price of risk, demand for investment falls short of supply; and as $r$ gets smaller, the curve approaches (under assumption (36a)) the vertical line $r_{\min }$, below which, even at an infinite price of risk, there is excess demand for investment goods (see Figure IV). Along the investment goods

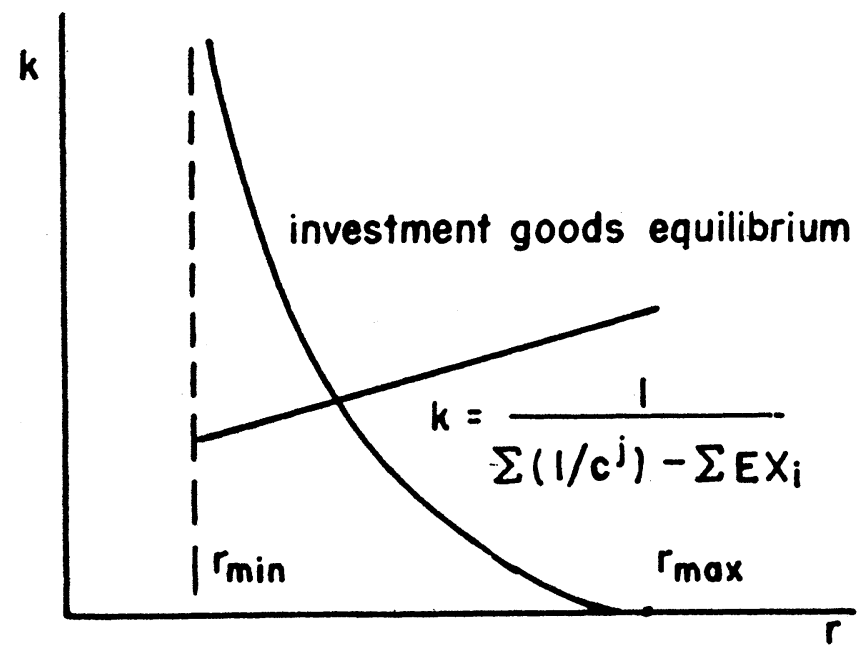

Figure IV

Determination of Equilibrium $(k, r)$ for Quadratic Utility Function

7. This will clearly be satisfied if for any $i, \lim _{I_{i} \rightarrow 0} h_{i}{ }_{i}\left(I_{i}\right) \rightarrow \infty$ and for all $i, \lim _{I_{i} \rightarrow \infty} h^{\prime}{ }_{i}\left(I_{i}\right) \rightarrow 0$. 
equilibrium curve, it can be shown that $\mathbf{\Sigma} E X_{i}$ is an increasing function of $r$, from which it follows that along (14), $k$ is an increasing function of $r^{8}$ Clearly, the two curves must intersect once and only once.

\section{E. Pareto Optimality}

We now wish to compare the market equilibrium described in the previous subsection with the optimal allocation. We wish to maximize $U\left(E Y, \sigma_{Y}\right)$, where $\sigma_{Y}$ is defined in (31). Optimality requires

$$
h_{i}^{\prime}-h_{s}^{\prime}=-\frac{U_{2}}{U_{1}} \frac{g_{i} g_{i}^{\prime}}{g_{R}}=-\frac{U_{2}}{U_{1}} \cdot \frac{1}{2 g_{R}} \cdot \frac{d g_{i}{ }^{2}}{d I_{i}} .
$$

The differences between the marginal increase in average returns of the $i^{\text {th }}$ asset and the safe asset should be proportional to the marginal increase in variance, with the proportionality factor being the marginal rate of substitution divided by twice the standard deviation of the risky assets. This should be contrasted with the market equilibrium, which may be written, using (22) and (28), as

$$
h^{\prime}{ }_{i}-h_{s}^{\prime}=-\frac{U_{2}}{U_{1}} \frac{2 g_{i}^{\prime} g_{i}}{g_{R}}=-\frac{U_{2}}{U_{1}} \cdot \frac{1}{g_{R}} \cdot \frac{d g_{i}^{2}}{d I_{i}} .
$$

The equations are identical, except that the proportionality factor is twice that of the optimal allocation, i.e., the "price" of risk is twice what it should be.

The resulting effect on the resource allocation may be seen diagrammatically as follows.

Assume that all the risky firms are identical. Recall from the previous subsection that the opportunity locus is concave. Then the optimal point $P$ is simply the tangency of the indifference curve with the opportunity locus (Figure II). It is clear from a comparison of $P$ and $C$ that $P$ always lies to the right of $C$ : the market allocation always results in less investment in the risky industries than the optimal allocation.

8. Along the locus defined by (10), we require

But from (30)

$$
\Sigma \frac{d I_{i}}{d r}=\Sigma \frac{\partial I_{i}}{\partial r}+\frac{d k}{d r} \Sigma \frac{\partial I_{i}}{\partial k}=0 \text {. }
$$

$$
\frac{d I_{i}}{d r}=\frac{1+\frac{d k}{d r} \frac{\left(h_{i}^{\prime}-r\right)}{k}}{h^{\prime \prime}{ }_{i}-k\left(g^{\prime \prime}{ }_{i} g_{i}+g_{i}^{\prime}{ }^{2}\right)} .
$$

By (26) the denominators are all negative while the numerator is a monotonic function of $h^{\prime}$, so that for those firms with large $h^{\prime}, d I_{1} / d r>0$, and conversely for firms for small $h^{\prime}$. But $d E X_{i} / d r=\Sigma h^{\prime}{ }_{i} d I_{i} / d r$ and the result is immediate. 
More generally, it is possible to show that, although the market allocation always lies along the social opportunity locus, ${ }^{9}$ i.e., is "efficient," it always results in too much investment in the safe industry.

\section{F. Nonindependent Returns}

When, however, we drop the assumption of independence, the economy will not even be "efficient," i.e., it will operate "below" its mean variance opportunity locus. To see this, assume that the returns to any firm may be described by

$$
X_{i}\left(\theta, I_{i}\right)=h_{i}\left(I_{i}\right)+g_{i}\left(I_{i}\right) \epsilon_{i}(\theta)+m_{i}\left(I_{i}\right) M(\theta)
$$

where

$$
E \epsilon_{i}=E M=0
$$

so

(38b) $\quad E X_{i}=h_{i}$.

\section{Moreover, ${ }^{1}$}

$$
\begin{aligned}
& E_{\epsilon_{i} \epsilon_{\mathrm{j}}}=0, E_{\epsilon_{i}} M(\theta)=0 \\
& E M(\theta)^{2}=1, E_{\epsilon_{i}}{ }^{2}=1
\end{aligned}
$$

so

$$
E\left(X_{i}-E X_{i}\right)^{2}=g_{i}^{2}+m_{i}^{2} .
$$

$M(\theta)$ is a market factor common to all firms (the state of the business cycle). (38) states that the residual variance after taking out the common market factor is independent across firms.

Then the market valuation for the $i^{\text {th }}$ firm is (substituting (38) into (19))

$$
V_{j}=\frac{h_{i}-k\left(g_{i}^{2}+m_{i}^{2}+m_{i} \sum_{i \neq j}^{\Sigma} m_{j}\right)}{r} .
$$

There are three factors in the determination of the value of a firm: the mean, the variance, and the correlation with the "business cycle" of the returns of the firm.

If the firm maximizes the value of the original shareholders' equities, taking the interest rate, the risk discount factor, and the investment of the other firms as given (so that $\underset{i \neq j}{\mathbf{s}} m_{j}$, the "magnitude

9. Efficiency requires

$$
\min \Sigma g_{i}^{2}
$$

i.e.,

subject to $\Sigma h_{1}=$ constant

$$
\nu g^{\prime} g_{i}=h^{\prime}{ }_{i}-h^{\prime} s
$$

where $\nu$ is a proportionality factor. But the market investment equations (28) are of the same parametric form, and hence the market allocation is efficient.

1 . The conditions given in (38d) are simply normalizations. 
of the cyclical fluctuations," due to the other firms, is given), then

$$
h_{i}^{\prime}-r=k\left(2 g_{i} g^{\prime}{ }_{i}+2 m_{i} m_{i}^{\prime}+m_{i}^{\prime} \underset{i \neq j}{\sum_{j}} m_{j}\right) \text {. }
$$

The mean variance efficiency frontier is, on the other hand, defined parametrically by ${ }^{2}$

$$
h_{i}^{\prime}-r=\kappa\left(g_{i} g^{\prime}{ }_{i}+m_{i} m^{\prime}{ }_{i}+m^{\prime}{ }_{i \neq j} \sum_{j}\right)
$$

A comparison of (40) and (41) immediately yields the result that the market allocation places twice as much weight on the own variance relative to the covariance terms as it "ought to," i.e., as it would along the efficiency frontier; indeed, it should be clear that optimality requires that the firm pay no more attention to its own variance than to the covariance terms - in equilibrium all the securities are "lumped" together in one mutual fund. (41) confirms this.

The reason for this misallocation is that the covariance of the firms with one another acts very much like an externality. A change in the level of investment of one firm affects the value of all other firms; although it may affect the value of any individual firm very little, when added up over all the firms, the effect is nonnegligible.

The implications of this for the direction of the misallocation of investment are clear. Assume for instance that there are two risky industries. For simplicity, let $h_{i}=h^{\prime}{ }_{i} I_{i}, m_{i}=m_{i}^{\prime} I_{i}, g_{i}=g_{i}^{\prime} I_{i}$, with $h_{i}^{\prime}$, $m^{\prime}{ }_{i}, g^{\prime}{ }_{i}$ constants. Assume that the two industries have the same mean returns. Then, letting $\sigma_{x i}{ }^{2}=m_{i}{ }^{2}+g_{i}{ }^{2}$, variance per dollar invested,

$$
\left(\frac{I_{i}}{I_{j}}\right)_{M}-\left(\frac{I_{i}}{I_{j}}\right)_{0}=\frac{m_{i}^{\prime} m_{j}^{\prime}\left({\sigma_{x_{i}}}^{2}-\sigma_{x_{j}}{ }^{2}\right)}{\left(2 \sigma_{x_{i}}{ }^{2}-m_{i}^{\prime} m_{j}^{\prime}\right)\left(\sigma x_{i}{ }^{2}-m_{i}^{\prime} m_{j}^{\prime}\right)}
$$

where $\left(I_{i} / I_{j}\right)_{M}$ and $\left(I_{i} / I_{j}\right)_{0}$ are the market and optimal ratios of investment in industry $i$ to that in $j$. Thus, if $m_{i} m_{j}>0$, i.e., the two are positively correlated, the market allocates relatively too little to the low variance industry (provided $m_{j}^{\prime}<m_{i}^{\prime}+g_{i}{ }^{2} / m_{i}^{\prime}$ or $m_{j}^{\prime}>m_{i}^{\prime}+$ $\left.2 g_{i}^{\prime 2} / m_{i}{ }^{\prime}\right)$. Other cases are left to the reader.

(40) and (41) have one interesting and important implication: observe that if the own variance term is small relative to the covari-

2. We wish to

$$
\begin{array}{cl}
\max _{\text {ax }} & \Sigma h_{i}\left(I_{i}\right)+h_{s}\left(I-\Sigma I_{i}\right) \\
\text { subject to } & \Sigma g_{i}^{2}+2 \Sigma m_{i} m_{j}=\sigma^{2} .
\end{array}
$$

Forming the Lagrangian

$$
L=\Sigma h_{i}+h_{s}-\frac{\kappa}{2}\left(g_{i}{ }^{2}+2 \Sigma m_{i} m_{j}-\sigma^{2}\right)
$$

and taking the derivative with respect to $I_{i}$, we obtain (41). 
ance terms, the level of investment yielded by (40) will be approximately that yielded by (41); indeed, not only are we "approximately" efficient, but we are "approximately" Pareto optimal.

\section{Choice of Technique}

In the preceding section, we considered the market allocation of investment, assuming that the firm had no choice of technique. An equally important question is, do market value-maximizing firms make the "correct" decisions about the choice of technique; i.e., if a firm can reduce its own variance - but only at the expense of a reduction in its mean or an increase in its collinearity with the market - will it make the correct "trade-off" calculations?

The results we obtain here very much parallel those obtained in the previous section: if all firms are independent, the economy operates on its efficiency frontier; the only distortion arises from a disparity between the marginal rate of transformation between mean and standard deviation (the slope of the efficiency frontier) and the marginal rate of substitution (the slope of the indifference curve). On the other hand, if the firms are not perfectly independent, the economy will not even be on its mean variance frontier - too much weight will be placed on the own variance terms relative to the covariance terms.

\section{A. Independent Firms}

Because when firms are independent in the mean variance model, the market valuations depend only on the mean and variance of output, we can completely describe the set of (relevant) technologies by the function

$$
I_{i}=\Omega_{\mathrm{i}}\left(\sigma_{x_{i}}, E X_{i}\right) \text {. }
$$

For a fixed level of investment, we can decrease the variance by decreasing the mean, while increasing the level of investment gives us

3. That is, Pareto optimality requires

$$
h^{\prime}{ }_{\imath}-r=\left(-\frac{U_{2}}{U_{1}}\right)\left(\frac{1}{\sum_{i} g_{i}{ }^{2}+\sum_{i} \sum_{j} m_{i} m_{j}}\right)^{1 / 2}\left(g_{i} g^{\prime}{ }_{\imath}+m^{\prime}{ }_{\imath} \mathbf{\Sigma} m_{j}\right)
$$

while (40) yields (using (22))

$$
h^{\prime}{ }_{\imath}-r=\left(-\frac{U_{2}}{U_{1}}\right)\left(\frac{1}{\Sigma g_{i}{ }^{2}+\Sigma \Sigma m_{i} m_{j}}\right)^{1 / 2}\left\{\left(g_{i} g^{\prime}{ }_{i}+m^{\prime}{ }_{i} \Sigma m_{j}\right)+\left(g_{i} g^{\prime}{ }_{i}+m_{\imath} m^{\prime}{ }^{\prime}\right)\right\} \text {. }
$$

If $g_{i} g^{\prime}{ }_{i}+m_{i} m^{\prime}{ }_{i} / g_{i} g^{\prime}{ }_{i}+m^{\prime}{ }_{i} \Sigma m_{j}$ is small, then the two equations are approximately the same. 




Figure Va

Choice of Technique: Independent Firms

a higher mean and standard deviation. See Figure Va. A valuemaximizing firm taking $k$ and $r$ as given chooses $\sigma_{x_{i}}$ and $E X_{i}$ so that

$$
\begin{aligned}
& \frac{1}{r}=\frac{\partial \Omega_{i}}{\partial E X_{i}} \\
& -\frac{k}{r}=\frac{1}{2 \sigma_{x_{i}}} \frac{\partial \Omega_{i}}{\partial \sigma_{x_{i}}},
\end{aligned}
$$

i.e.,

$$
\frac{\partial E X_{i}}{\partial \sigma_{x_{i}}}=-2 k \sigma_{x_{i}}
$$

Efficiency requires

$$
\begin{array}{ll}
\min & \mathbf{\Sigma} \sigma_{x_{i}}{ }^{2} \\
\text { s.t. } & \mathbf{\Sigma} E X_{i}+h_{s}\left(I-\Sigma \Omega_{i}\right)=M,
\end{array}
$$

i.e., if $q$ is the Lagrange multiplier associated with the above con. straint,

$$
2 \sigma_{x_{i}}=q h_{s}^{\prime} \frac{\partial \Omega_{i}}{\partial \sigma_{x_{i}}}, 1=h_{s}^{\prime} \frac{\partial \Omega_{i}}{\partial E X_{i}}
$$

from which it immediately follows that the competitive economy is efficient but not optimal.

\section{B. Nonindependent Returns}

When the firms are not independent the specification of the technology is only slightly more complicated. We assume for sim-

4. To ensure that we have interior solution, all we require is that at fixed $I_{i}$, successive decreases in standard deviation can only be purchased by successively larger decreases in $E X_{i}$. 
plicity that there is only a single market factor common to all firms and that output in the different state of nature (for all $I_{i}$ and production plans) can be described by an equation of the form (38). Then, we can describe the technology by

$$
I_{i}=\Omega_{i}\left(m_{i}, \epsilon_{i}, E X_{i}\right) .
$$

Value maximization will result in

$$
\begin{aligned}
& \frac{\partial \Omega_{i} / \partial \epsilon_{i}}{\partial \Omega_{i} / \partial E X_{i}}=\frac{\partial V / \partial \epsilon_{i}}{\partial V / \partial E X_{i}}=2 k \epsilon_{i} \\
& \frac{\partial \Omega_{i} / \partial \epsilon_{i}}{\partial \Omega_{i} / \partial m_{i}}=\frac{\partial V / \partial \epsilon_{i}}{\partial V / \partial m_{i}}=-\frac{\epsilon_{i}}{\frac{1}{2} \sum_{i \neq j} m_{j}+m_{i}} .
\end{aligned}
$$

Efficiency (i.e., to be along the mean variance frontier) requires (where $\kappa$ is a proportionality factor common to all $i$ )

$$
\begin{aligned}
& \frac{\partial \Omega_{i} / \partial \epsilon_{i}}{\partial \Omega_{i} / \partial E X_{i}}=2 \kappa \epsilon_{i} \\
& \frac{\partial \Omega_{i} / \partial \epsilon_{i}}{\partial \Omega_{i} / \partial E m_{i}}=\frac{\epsilon_{i}}{\sum_{i \neq j} m_{j}+m_{i}} .
\end{aligned}
$$

Comparing (46b) and (47b), we see again that the value-maximizing firm puts too little weight on the covariance term $\left(\sum_{i \neq j} m_{i}\right)$. The two solutions are compared in Figure $\mathrm{Vb}$. (It is likely to be increas-

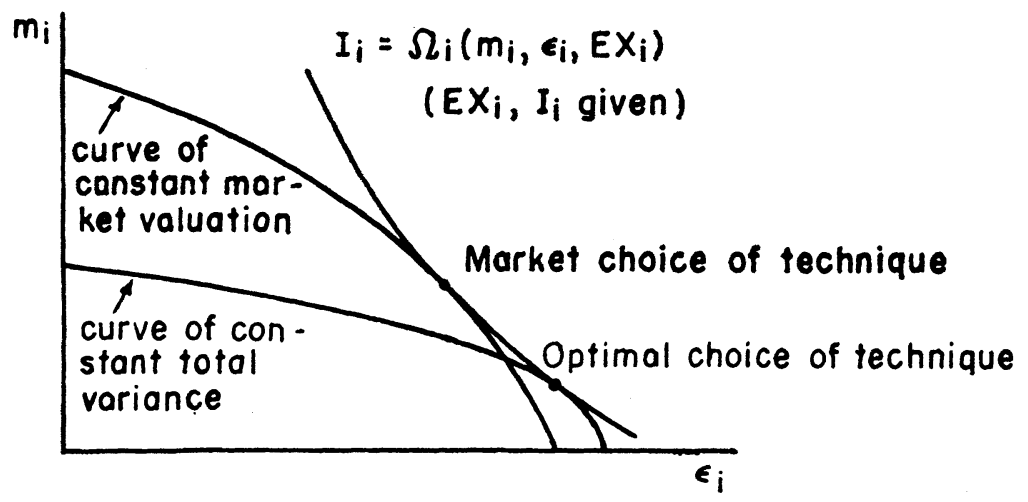

Figure Vb

Choice of Technique: Own Variance versus Correlation with Market

ingly difficult to provide outputs with lower and lower own variance, as well as increasingly difficult to provide outputs that are less and less correlated with the market. Hence, at constant $I_{i}$ and $E X_{i}, \boldsymbol{\epsilon}_{i}$ is assumed to be a convex function of $m_{i}$.) 
An immediate corollary of these results is the following: if we confront the economy with a choice between two different projects costing the same amount, identical in mean, but differing in their own variances and covariances from other projects, the total market variance will be independent of which firm undertakes the project; but if we confront different firms in the economy with the same choice, the decision made will in general differ from firm to firm.

Even when the own variance terms are small relative to the covariance terms, the firm's "trade-off" between $\epsilon_{i}$ and $m_{i}$ is twice what it should be. Of course, if $\epsilon_{i}$ is small for all $i$, the consequences of this may be negligible. In the limiting case where $\epsilon_{i} \equiv 0$ (the technology is of the form $I_{i}=\Omega_{i}\left(m_{i}, E X_{i}\right)$ ), the economy is "approximately" efficient and Pareto optimal if there are a large number of firms $\left(m_{i}\right.$ is much less than $\left.\underset{i \neq j}{\mathbf{N}} m_{j}\right)$.

\section{Discrete Choices}

These results are rather gratifying. They accord with our intuition: if the only "risk" a firm is "selling" is associated with a common market factor and if the individual firm is small relative to the market as a whole, we obtain the usual competitive results on Pareto optimality. When the firm is "selling" in addition some risk not associated with the market, it places too much emphasis on this.

To obtain these results, we assumed that the firm faced a "continuum" of techniques. In practice firms are likely to face a set of discrete choices, or, if there is a "continuum" of techniques, it is likely to be defined over a narrower range of values of $\left(\epsilon_{i}, m_{i}, E X_{i}\right)$, so that corner solutions are more likely to occur. The emphasis on own variance may well result in the wrong (from the social point of view) decisions with respect to production plans (see Figure $\mathrm{Vc}$.

\section{Structural Inefficiencies}

But still more striking is the result that, even if each firm takes the action that maximizes social welfare (taking the behavior of the other firms in the economy as given), the economy may not arrive at an optimal equilibrium. To see this, consider the following simple example. There are two industries. Each firm has available to itself two alternative investment projects, in the first industry $A$ and $B$, in the second, $C$ and $D$. There are a given number of firms and the level of investment in each firm has already been fixed. The sole 


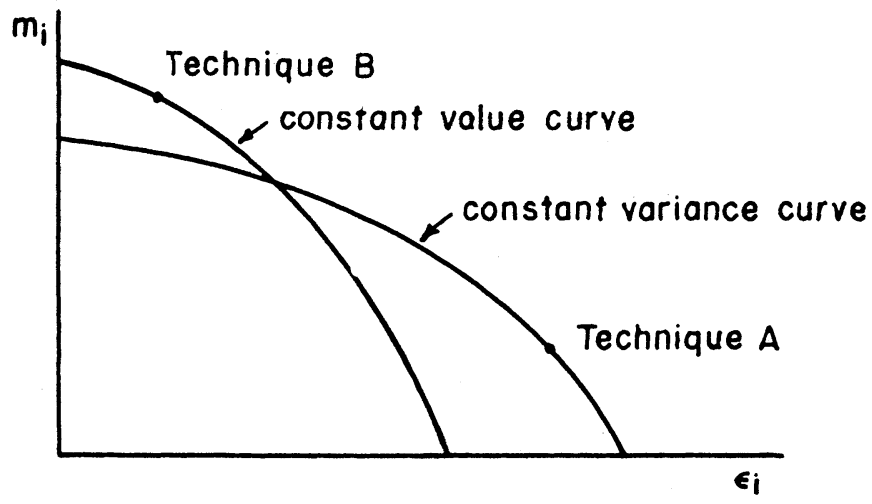

Figure Vc

Choice of Technique: Two Alternatives

question facing each firm is whether, in the first industry, to use $A$ or $B$, and in the second, to use $C$ or $D$. The returns to all firms in the first industry, regardless of the technique they use, are independent, and similarly for the second. The mean returns to all projects are identical, and the own variances are identical. The projects differ then only in their covariances from projects of the other industry. Let $C_{i j}$ be the covariance between the returns to the $i^{\text {th }}$ project of any firm in the first industry and the $j^{\text {th }}$ project of any firm in the second industry. We make the following assumptions about $C_{i j}$ : ${ }^{5}$

$$
\begin{aligned}
& C_{A C}<C_{A D} \\
& C_{B C}>C_{A C} \\
& C_{B D}<C_{B C} \\
& C_{A D}>C_{B D} \\
& C_{A C}<C_{B D}
\end{aligned}
$$

Assume that each firm, given the decisions of all the other firms, chooses the project (technique) that minimizes total social variance. (Alternatively, we may let it choose the project that maximizes its value.)

In this economy, then, there are two equilibria: In one, all of the firms in the first industry choose $A$, while all in the second choose $C$; while in the other equilibrium, all the firms in the first industry choose $B$, while all in the second choose $D$. To see this, we observe that, because of our assumptions of independence within an

5. It is easy to show that these assumptions are not inconsistent with the positive definiteness of the variance-covariance matrix. 
industry, and identical means and own variances, the only thing that matters is the covariance with the projects undertaken by members of the other industry. If all the firms in the first industry choose $A$, all the firms in the second would choose $C$, since $C_{A C}<C_{A D}$. Conversely, if all the firms in the second industry choose $C$, all the firms in the first would choose $A$, since $C_{A C}<C_{B C}$. Similarly, if all the firms in the first industry choose $B$, in the second they would choose $D$, since $C_{B D}<C_{A D}$; and if all the second choose $D$, all the first would choose $B$, since $C_{A D}>C_{B D} \cdot{ }^{6}$

But in the equilibrium $(A C)$ everyone is better off than in the equilibrium $(B D)$, since $C_{A C}<C_{B D}$.

One might have thought that if firms merged, one firm from one industry merging with one firm of the other, the resulting coordination in choice of technique would ensure that the allocation $(A C)$ would be adopted. But this is incorrect; for the important interactions are between a given firm in, say industry 1, and all the other firms in industry 2. What any single firm in industry 2 does will not in general affect the choice of technique of the firms in industry 1. To ensure optimality, there must be coordination of choice of projects (techniques) over the entire economy: In the presence of uncertainty, but in the absence of a complete set of markets for contingent claims (Arrow-Debreu) markets, we encounter important difficulties in efficient decentralization.

This is an example of what might be called a structural inefficiency in the economy. It cannot be corrected by marginal changes on the part of any single producer.

\section{Remarks on Alternative Models of Market Equilibrium}

Besides the Arrow-Debreu model, to which reference has been made in the introductory remarks, there is one other precisely formulated model of the stock market, that of Diamond. ${ }^{7}$ The central result of his study was that the allocation of investment was a (constrained) Pareto optimal, in marked contrast to the results obtained here. One can perhaps best understand his model by way of an analogy to the automobile market. An automobile may be viewed as a composite commodity ${ }^{8}$ if there were enough different kinds of

6. We have formulated the problem as if each could choose either one project or the other. But exactly analogous results obtain if the firm is allowed to choose the proportions in which to invest in the two projects, although further restrictions in addition to (48) need to be imposed.

7. Op. cit.

8. As in K. J. Lancaster, "A New Approach to Consumer Theory," 
automobiles one could infer the market, valuation of tail fins, chrome, alternative sizes, vinyl seats, cloth seats, etc. But if the kind of automobile that a given producer is manufacturing has already been determined, these "constituent" prices are of no interest to him. His only concern is the price of the composite commodity that he produces. If the producer should act like a price taker, then it is easy to see that the market equilibrium would be a "constrained" Pareto optimal, i.e., given the kinds of automobiles produced, the amounts produced are "correct." Diamond, following Modigliani and Miller, recognized that the same applies to risky assets. If the firm produces only one pattern of returns across the states of nature, it needs to know only the "price" of a unit of that pattern of return. Indeed, we can completely eliminate any explicit mention of uncertainty on the part of either consumers or producers; consumers' expected utility is simply a function of the number of "units," $S_{i}$, of each of the patterns of return they own $-E U=\phi\left(S_{1}, \ldots, S_{n}\right)$ - and firms' market valuation is simply a function of the number of units they supply: $V_{i}=V_{i}\left(S_{i}\right)$. If firms act "competitively," i.e., take the price of a unit of the pattern of return as given, it is clear that the equilibrium will be a constrained Pareto optimal.

The limitations of this model are clear: (a) it provides no answer to the fundamental question of the choice of technique; (b) it provides an answer to the question of the level of investment only under the stringent condition that the pattern of returns not change as the level of investment of the firm changes (multiplicative uncertainty); in fact, a change in scale of operation often entails a different production process with different patterns of return; (c) the behavioristic rule on which it is based is seriously open to question: is it reasonable to assume that when firms are not perfectly correlated they believe that doubling their scale will double their market value? Or is it more reasonable to assume that they recognize what will in fact normally be the case, that the firm that is twice as large will have a value less than twice as great? ${ }^{9}$

Journal of Political Economy, vol. 74 (April 1966), pp. 132-57, and Z. Griliches, "Hedonic Price Indexes Revisited: Some Notes on the State of the Art," Proceedings of the American Statistical Association, 1967, Business and Economics Statistics Section, pp. 324-32.

9. A further difficulty, which V. Smith has emphasized to me, is that, except in the case of the mean variance model with homogeneous expectations analyzed here, the assumption of no bankruptcy will in general be violated by value-maximizing firms; the financial policy of the firm does make a difference; the models as presently formulated are then incomplete, since they do not explain the determination of the financial policy of the firm. 
The Arrow-Debreu model and the Diamond model are both attempts to analyze uncertainty by formulating a model that is identical in all essential respects to the conventional model without uncertainty. This, I suspect, gives us more insight into the limitations of the conventional model than into the actual workings of our economy.

We have attempted to formulate a simple alternative model. The example that we have analyzed in detail has employed the familiar mean variance model; this is both a limitation and a strength of the model. For it is likely that it is in terms of some such simple parametrizations that firms make their decisions. The model has the further advantage that firms do act as price takers: they take as given the market rate of interest and the risk discount factor. Indeed, the "pricing" system that we have suggested firms use has all the properties of a normal pricing system; in particular, in equilibrium the values of all firms may be calculated in terms of the same valuation function (just as in the Arrow-Debreu model). ${ }^{1}$ It has the further property that in certain limiting cases, where there is no choice of technique and the own variances are negligible relative to the covariances with the other firms in the economy, the market allocation is approximately Pareto optimal; in that case, firms can simply ignore that part of their own variance which is uncorrelated with the rest of the market. Both casual empiricism and econometric investigation suggest, however, that own variances are significant in explaining market valuations; ${ }^{2}$ that firms are "risk averse" with respect to investment opportunities that are

1. It is at this point that alternative "pricing" schemes that have sometimes been suggested fail. For instance, it has been argued that firms perceive themselves as selling "mean" and "standard deviation." Thus, if the firm were to double its size, it would double its value; as a result, the market allocation will be Pareto optimal. But there is no "price" of standard deviation common to all firms that can correctly "predict" the value of the firm; e.g., in the case of independence, if the firm "priced" units of standard deviation at $k \sigma_{x_{i}}$, it would correctly "explain" its market value, but this price will differ from firm to firm. A similar suggestion is that the firm perceives itself as selling not standard deviation but "contributions to the total variance of market wealth." This fails for similar reasons, as explained at greater length in the Appendix.

2. See, for instance, G. W. Douglas, "Risk in the Equity Markets: An Empirical Appraisal of Market Efficiency," Yale Economic Essays, vol. 9 (Spring 1969), pp. 3-45, and J. Lintner, "Security Prices and Risk: The Theory and a Comparative Analysis of A.T. and T. and Leading Industrials," a paper presented at the conference on the Economics of Regulated Public Utilities, June 24, 1965 (as cited by Douglas). In fact, both of those studies suggest that firms ought to put even more weight on their own variance than they do in our model. See also M. H. Miller and M. Scholes, "Rates of Return in Relation to Risk: A Reexamination of Some Recent Findings," mimeo, Chicago, 1970. 
uncorrelated with the business cycle; ${ }^{3}$ and that, although the market for the trading of securities is probably one of the most competitive markets in existence, the firms do not act as perfect competitors in issuing securities: they are aware that (at least in the short run corresponding to the time scale of our model) increasing their size will increase their market valuation less than in proportion. It is these characteristics of the markets for risky assets that we have attempted to capture in our model.

It seems clear that the result of the model, that the market economy will not be Pareto optimal, ${ }^{4}$ both because firms fail to take adequate account of covariances with other firms and because they perceive that their value will not increase in proportion to their scale in the short run, suggests that the stock market may not be as "efficient" a mechanism for allocating resources as has until now been thought to be the case and, in particular, as has been suggested by the previously formulated models of the stock market. Extensions of the model, allowing, for instance, for free entry of firms, reinforce the results reported here. In that case, not only will the total level of investment in the risky industries be too small, but also the number of firms will not be optimal. The economy will be operating below its mean variance frontier (allowing for a variable number of firms) even when the firms are independent.

\section{Concluding Remarks}

That a competitive economy would lead, as if by an invisible hand, to a Pareto-optimal allocation of resources has long been held to be one of its most attractive features. In the context of a static economy with no uncertainty, rigorous proofs of this result, as well as its converse, that every Pareto-optimal allocation can be sustained by a competitive equilibrium (with some redistribution of initial endowments), have been presented; and the limitations on the theorem, the importance of externalities, increasing returns to scale (nonconvexities), and public goods have been extensively discussed. Arrow and Debreu have shown, moreover, how this model may formally be extended to include dynamic economies and uncertainty. But the markets required by this model are not present in any observed economy. Indeed, we have considered a case where

3. If own variance terms were small relative to the correlation with the market, firms could simply ignore the own variance terms; they would be diversified out by the market.

4. Except in the limiting cases already noted. 
all individuals would purchase Arrow-Debreu securities in the same proportions, were they available. As far as consumers are concerned, they are perfectly content to have the securities provided by a single mutual fund. In such a situation, if there were even the slightest increase in costs of transacting in separate securities as opposed to mutual funds, it is likely that only a limited number of such markets would exist. Yet the prices that the ArrowDebreu markets would provide for the guidance of firms in making decisions are essential for firms to make the correct allocative decisions.

In analyzing the allocation of investment resources in an economy with a stock market, we face two questions:

1. Do the prices for the different capital goods (different securities) correctly reflect the social returns from those goods (securities), or do the prices simply reflect, as Keynes suggested they did, ${ }^{5}$ our expectations of what others' expectations will be of the price of the good (security) in the future? Indeed, Hahn and Shell and Stiglitz have argued that, in the absence of a complete set of future markets, the competitive allocation among alternative capital assets might not (indeed, from their analysis, it appeared likely that it would not) be efficient. ${ }^{6}$

2. Even if the prices for the different securities correctly reflect the social returns, will they lead to an efficient investment pattern? It is with this question that this paper has been primarily concerned. By limiting ourselves to a two-period model and by assuming for most of the analysis that all individuals are in agreement about the pattern of returns for each firm, we have been able to abstract from the first problem. Nonetheless, we have argued that the market's allocation of resources between safe and risky assets, the allocation among risky assets, and the choice of techniques will not be optimal.

The results suggest that the "invisible hand" of competition may not work as well as had been previously thought. In some sense, these limitations on the optimality of competitive markets are far more serious than the restrictions that had been noticed earlier, for we are concerned here with one of the most fundamental of all economic activities, the allocation of resource among alternative investment opportunities. Moreover, while externalities can be corrected

5. J. M. Keynes, The General Theory (New York: Harcourt, Brace, and World, 1936).

6. F. H. Hahn, "Equilibrium Dynamics with Heterogeneous Capital Goods," this Journal, vol. 80 (Nov. 1966), pp. 633-46; K. Shell and J. E. Stiglitz, op. cit. 
by the appropriate use of tax policy, public goods will necessarily be provided by the government; and if there were only a few increasing returns to scale industries, they could be either nationalized or regulated by the government, while the rest of the economy remained under private control; the problem of the competitive misallocation among alternative investment opportunities does not appear to be so easily corrected. Some of the problems that we have raised for the competitive economy are equally problems for the decentralized socialist economy. Whether in fact any centralized decision-making mechanism would, in practice, give a better allocation remains a moot question.

\section{APPENDIX}

An alternative valuation function, proposed by Fama ${ }^{7}$ among others, is that the firm values its contributions to expected market wealth and its contribution to the total variance of market wealth:

$$
V_{i}=\left(\frac{1}{r} \frac{\partial E X}{\partial I_{i}}-\frac{\kappa}{r} \frac{\partial \sigma_{x}}{\partial I_{i}}\right) I_{i}
$$

where $E X$ is the total average income (of all firms) and $\sigma_{x}{ }^{2}$ is total variance, and where $\kappa=U_{2} / U_{1}$, the marginal rate of substitution between mean and standard deviation. Firms are assumed to take $r$ and $\kappa$ as given. Fama concludes his analysis by arguing, "The important implication of all this is that in our two-parameter model, the shares of different firms are perfect substitutes, and no firm is unique in terms of the objects it brings to the capital market for sale," and "It is as if there were an (invisible) grand market overseer who calls out the prices consumers and firms require to make optimal decisions."

The one very special case in which those euphoric statements have some validity - that in which the technology has constant returns to scale (doubling investment doubles output in every state of nature $)^{8}$ - is the case where this valuation function is equivalent to that employed by Diamond and by Modigliani and Miller.

To see this, observe that if $g_{i}{ }^{2}$ is the own variance per unit of investment, $h_{i}$ is the average return per unit of investment, and $m_{i}$ is the covariance with all other firms (per unit of investment),

$$
\frac{\partial \sigma_{x}}{\partial I_{i}}=\left(I_{i} g_{i}^{2}+m_{i}\right) / \sigma_{x}, \frac{\partial E X}{\partial I_{i}}=h_{i}
$$

so that, rewriting (19), we obtain an equation of the form of (A.1)

$$
V_{i}=I_{i}\left\{h_{i}-\kappa \frac{\partial \sigma_{x}}{\partial I_{i}}\right\} / r
$$

7. E. Fama, "Risk, Returm, and Equilibrium," U. of Chicago, mimeo. 1968.

8. The analysis may easily be extended to the more general case of multiplicative uncertainty. 
where (with (22))

$$
\text { (A.3) } \quad \kappa=k \sigma_{x}=-U_{2} / U_{1} \text {. }
$$

Assuming that $\kappa$ and $\partial \sigma_{x} / \partial I_{i}$ are independent of the level of investment of the firm is equivalent to assuming that the value of the firm is proportional to investment. Thus the reason that this valuation function leads to Pareto optimality in this case has nothing to do with Fama's "two-parameter model," or the assumption that different securities are close substitutes for each other; rather it follows directly from the special nature of the technology and the price-taking behavior of firms, and is true without restriction as to the nature of the utility function. More generally, the value of the firm cannot be described by means of an equation of the form (A.1). (And if it can, there is no assurance that the resulting allocation will be optimal.) To see this, consider the following simple example. Assume that the $i^{\text {th }}$ firm's returns are independent of those of all other firms, and that

Then

$$
\begin{aligned}
E X_{i} & =h_{i} I_{i} \\
\sigma_{i} & =g_{i} I_{i}{ }^{\nu} .
\end{aligned}
$$

and

$$
\frac{\partial \sigma_{x}}{\partial I_{i}}=\frac{v I_{i}^{2 \nu-1} g_{i}^{2}}{\sigma_{x}}, \frac{\partial E X_{i}}{\partial I_{i}}=h_{i}
$$

$$
V_{i}=I_{i} \frac{\left(h_{i}-k g_{i}^{2} I_{i}^{2 \nu-1}\right)}{r}=\frac{\left(h_{i}-\kappa \frac{1}{\nu} \frac{\partial \sigma_{\infty}}{\partial I_{i}}\right) I_{i}}{r},
$$

which is not of the form of (A.1) except if $v=1$, i.e., the case of stochastic constant returns to scale.

This rule encounters further difficulties:

(i) It is not reasonable to assume $\partial \sigma_{x} / \partial I_{i}$ to be independent of $I_{i}$; consider the polar case where the firms all have independent distributions and $v=1$.

No matter how large the number of firms, neither $\partial\left(\partial \sigma_{x} / \partial I_{i}\right) /$ $\partial I_{i}$ nor $\partial l_{n}\left(\partial \sigma_{x} / \partial I_{i}\right) / \partial l_{n} I_{i}$ are zero:

$$
\frac{\partial\left(\partial \sigma_{x} / \partial I_{i}\right)}{\partial I_{i}}=\frac{g_{i}{ }^{2}}{\sigma_{x}}\left(1-\frac{I_{i}{ }^{2} g_{i}{ }^{2}}{\sigma_{x}{ }^{2}}\right) \rightarrow \frac{g_{i}{ }^{2}}{\sigma_{x}}
$$

if, as the number of firms gets large, the proportion of variance contributed by any single firm goes to zero; similarly

$$
\frac{\partial\left(\ln \partial \sigma_{x} / \partial I_{i}\right)}{\partial \ln I_{i}}=1-\frac{I_{i}{ }^{2} g_{i}{ }^{2}}{\sigma_{x_{i}}{ }^{2}} \rightarrow 1 \text {. }
$$

(ii) Moreover, how the firm is to evaluate its contribution to "risk," except in the special case of stochastic constant returns to scale, is never specified. It is not an easily observed market parameter. ${ }^{9}$

9. A further disadvantage of the approach sketched above is that it is not possible to extend it to the case where individuals have a risky wage income with, say, mean $E X_{w}{ }^{j}$ and standard deviation $\sigma_{w}{ }^{j}$. Assume for simplicity that 


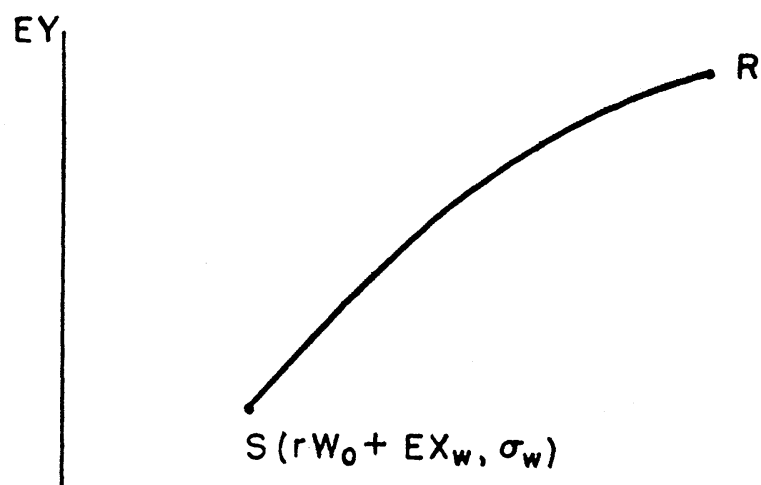

$\sigma_{\gamma}$

Figure VI

Opportunity Locus with Variable Wage Income

all securities are independent of all wage incomes. It will no longer be true that the opportunity locus is a straight line; rather, it is a positively sloped concave function (depicted in Figure VI), as can easily be verified. This means that the marginal rate of substitution between mean and standard deviation will differ between different individuals; there is no single market trade-off between mean and standard deviation as in the earlier discussion. Nonetheless, it can be shown that a valuation function of the form (19) remains valid.

Much of the discussion of portfolio analysis has been conducted in terms of the mean and standard deviation of the rate of return. Since it is consumption in which the individual is ultimately interested, it seems more natural to evaluate alternative investment programs in terms of the wealth (consumption) that they provide at the end of the period. Nonetheless, it should perhaps be pointed out that, if individuals evaluated alternative income streams in terms of the mean and standard deviation of the rate of return, the market allocation would not be Pareto optimal even if there were stochastic constant returns to scale in the risky industry and it acted as a price taker. To see this, assume that the safe industry has a decreasing returns to scale production function, and that there is a single risky industry that acted competitively. The social opportunity locus will then be a concave function, as depicted in Figure VII, with intercept with the vertical axis equal to $h_{s}^{\prime}(I)$. The individual takes the rate of interest as given, and hence faces a straight line opportunity locus. If the allocation to the safe industry is $I_{s}$, then the intercept with the vertical axis of the individual's opportunity locus is $h^{\prime}{ }_{s}\left(I_{s}\right)>h^{\prime}{ }_{s}(I)$ if $I_{s}<I$. Because of the assumption that there are stochastic constant returns to scale in the risky industry and that firms in the risky industry assume that the ratio of the value per unit of investment is independent of the level of investment, in competitive equilibrium the mean and standard deviations when investing in the risky asset alone are independent of the level of investment in the risky asset (and just equal to $h$ and $g$, respectively). If all individuals were identical, a competitive equilibrium would be a point such as $C$ in Figure VII, where the slope of the private opportunity locus equals the marginal rate of substitution between mean and standard deviation at the intersection of the private and social opportunity loci. But note that the optimal allocation again always lies at a higher level of investment in the risk industry than does the market allocation. 




In short, this alternative valuation function, in spite of its appeal to those who are convinced (on what basis it is hard to understand) of the optimality of the market allocation of investment in the presence of uncertainty, will not do; the only case where it is well defined and does "work" is the special case discussed in Section $\mathrm{V}$ where firms have no choice of technique and when the pattern of returns across the states of nature is unaffected by the scale of the firm. The limitations of this case have already been noted.

YALE UNIVERSITY 